\title{
Thermal Performance of Three Sided Artificially Roughened Double Duct Parallel Flow Solar Air Heater
}

\author{
Chander Kant ${ }^{1}$, Prashant Kumar ${ }^{2}$, Ankur Gill ${ }^{3}$ and Dhiraj Parkash Dhiman ${ }^{4}$ \\ ${ }^{1 \& 2}$ Department of Mechanical Engineering, National Institute of Technology, Hamirpur,Himachal Pradesh, India \\ ${ }^{3 \& 4}$ Department of Mechanical Engineering, Swami Vivekanand Institute of Engineering and Technology, Punjab, India \\ E-Mail: ankurgill6@gmail.com
}

\begin{abstract}
A solar air heater is basically a heat exchanger, which intercepts the incident solar radiation, converts it into heat and finally transfers this heat to a working fluid for an end use system. The mode of air flowing in the ducts of a solar air heater is one of the most significant aspects concerned with solar air heater which dominantly affect. A double duct parallel flow artificially roughened solar air heater with three sides of the absorber plate is investigated in the current study. Unlike the conventional model of solar air heater with only one sided roughened absorber plate, a novel solar air heater with three artificially roughened absorber plate is used so that the surface area of the absorber plate is increased which ultimately increases the rate of heat transfer. Additionally, a double duct parallel flow arrangement through inner and outer duct of solar air heater is considered order to enhance the heat transfer rate. A numerical investigation of the heat transfer and friction factor characteristics of a double duct parallel flow three sided artificially roughened solar air heater has been carried out. A commercial finite volume CFD code ANSYS FLUENT is used to simulate turbulent air flow through artificial roughened solar air heater. Governing equations of the fluid flow and heat transfer i.e. Navier-Stokes equation and energy equation are solved with RNG k- $\varepsilon$ turbulence model. Nine different configuration of square rib are studied with relative roughness pitch $(\mathrm{P} / \mathrm{e}=\mathbf{5 - 1 0})$ and relative roughness height $(\mathrm{e} / \mathrm{D}=\mathbf{0 . 0 3 - 0 . 0 6})$. The Reynold number of the flow is varied from 2500 to 16000.

Keywords: Solar Heater, CFD, Navier-stokes equation, ANSYS FLUENT
\end{abstract}

\section{INTRODUCTION}

\section{A. Solar air heater}

A solar air heater is basically a heat exchanger, which intercepts the incident solar radiation, converts it into heat and finally transfers this heat to a working fluid for an end use system [2]. Solar air system is a type of system which collects solar energy and transforms it into heat. The general idea is that the air is flowing through solar collector and heat from sun naturally raises the temperature of the air. The collector has on first layer of glazing which is exposed to sun. Circulation of the air in the building can be by natural driving forces (buoyancy effect) or by fan which is more certain. Optionally the fan can be powered by solar cell mounted on collector. Solar air heaters of many types have been developed in India. The application of these air heaters are limited to a few demonstration projects for food dehydration, and space heating. Space heating by solar air heaters and their use for natural ventilation are also common applications of solar air heater. Few major applications of the solar air heater are listed below:

1. Solar drying [3]: In India solar drying is employed for drying few major crops.

a. Paddy drying: The most adopted drying method after parboiling is the traditional open sun drying. The moisture content is reduced up to $16 \%$. Hot air drying with temperatures between $60^{\circ} \mathrm{C}$ and $80^{\circ} \mathrm{C}$ is useful and for that solar air heaters in standalone mode or in hybrid mode can be employed.

b. Timber drying: The solar kilns are employed to season timber for handicrafts, furniture, doors and windows. The feedback obtained was satisfactory and the economics are very attractive.

c. Drying of cash crops: Some of the cash crops like Tea, Coffee, Spices, Cardamom and Cashew are major foreign exchange earners. Use of solar air heaters for drying process in the production of these cash crops can provide an impulse to the solar energy programme in the country.

2. Space heating [3]: Space heating is required in high mountain regions in the North and North-Eastern Himalayas during the winter periods. Natural convection based solar air heaters, known as thermo-syphon air panels have been employed for space heating in Leh. Large scale experimentation with solar air heaters for space heating has not been undertaken in India so far.

\section{B. Solar collectors}

A solar collector is a special kind of heat exchanger that transforms solar radiant energy into heat. A solar collector differs in several respects from more conventional heat exchangers. The latter usually accomplish a fluid-to-fluid exchange with high heat transfer rates and with radiation as an unimportant factor. In the solar collector, energy transfer is from a distant source of radiant energy to a fluid. The flux of incident radiation is, at best, approximately $1100 \mathrm{~W} / \mathrm{m}^{2}$ (without optical concentration), and it is variable. The wavelength range is from 0.3 to $3 \mu \mathrm{m}$, which is considerably shorter than that of the emitted radiation from 
most energy-absorbing surfaces. Thus, the analysis of solar collectors presents unique problems of low and variable energy fluxes and the relatively large importance of radiation.

Broadly solar collector can be classified as:

1. Flat plate collectors.

2. Concentrating Collectors.

\section{Flat plate collectors}

Flat plate collectors are most widely used as solar collectors due to its easily manufacturing and low cost. They are mechanically simpler than concentrating collectors. They are in the application as early as in second world war times used by Germany. Flat-plate collectors can be designed for applications requiring energy delivery at moderate temperatures, up to perhaps $100^{\circ} \mathrm{C}$ above ambient temperature. They use both beam and diffuse solar radiation, do not require tracking of the sun, and require little maintenance. The major applications of these units are in solar water heating, building heating, air conditioning, and industrial process heat. Passively heated buildings can be viewed as special cases of flat-plate collectors with the room or storage wall as the absorber.

\section{Concentrating collectors}

To deliver energy at temperatures higher than those possible with flat-plate collectors. Energy delivery temperatures can be increased by decreasing the area from which heat losses occur. This is done by interposing an optical device between the source of radiation and the energy-absorbing surface. The small absorber will have smaller heat losses compared to a flat-plate collector at the same absorber temperature. Many designs have been set forth for concentrating collectors. Concentrators can be reflectors or refractors, can be cylindrical or surfaces of revolution, and can be continuous or segmented. Receivers can be convex, flat, or concave and can be covered or uncovered. Many modes of tracking are possible.

\section{LITERATURE REVIEW ON SOLAR AIR HEATERS}

A comprehensive literature survey on solar air heaters has been given in this section. A summary of the findings in the history of solar air heater is presented.

\section{A. Augmentation of heat transfer from the absorber plate}

The performance of a f lat plate collector either operated under single or double air pass has been found to depend strongly on the rate of incident solar radiation, the losses from the absorber surface and the rate of heat transfer from absorber plate to the air. The poor heat transfer rate from the absorber plate to air in the duct results in relatively higher absorber plate temperature leading to higher thermal losses to the environment. These losses can be reduced by lowering the absorber plate temperature by increasing the heat transfer coefficient between absorber and air. There are several way by which the temperature of the absorber can be reduced. This objective can be achieved by using:

1. extended surfaces on the absorber surfaces,

2. porus media air flow duct and

3. artificial roughness.

\section{Extended surfaces}

The extended surfaces in the form of fins, fins plus baffles or v-corrugations on the absorber plate help in two ways; firstly by increasing turbulence and secondly by increasing the area of heat transfer and hence more heat transfer occurs. In an experimental study by Bevil Brandt [4] on two square collectors with absorber plate having 96 pa rallel fins of aluminum $61 \mathrm{~cm}$ long $6.35 \mathrm{~cm}$ high and $0.635 \mathrm{~cm}$ apart, a gain in efficiency has been reported.

Kuzay et al. [5] investigated the performance of solar air heaters with straight and staggered fins. The staggered arrangement was fabricated from U-shaped aluminum fins, $2.5 \mathrm{~cm}$ high with the U-section tapered and the spacing ranging from $0.6 \mathrm{~cm}$ to $1.0 \mathrm{~cm}$. The staggering was done after every $1.9 \mathrm{~cm}$. Efficiencies of $74 \%$ and $49 \%$ respectively were reported with temperature rise of $26{ }^{\circ} \mathrm{C}$ and $73^{\circ} \mathrm{C}$.

Matrawy [6] showed that the efficiency of solar air heater can be enhanced by using the metal vanes, which are attached between the absorber and bottom plate of the collector. The comparison between the performance of a collector having box frame absorber and one having a finned plate absorber was carried out. The result show that a higher efficiency can be achieved with the use of metal vanes.

Ryan et al. [7] investigated the thermal performance of flat plate, v-corrugated and finned solar air collectors. It was found that the thermal performance of v-groove collector is $7-12 \%$ higher efficiency than flat-plate collectors. Moreover, study was carried out to determine the optimum conditions of the three collectors. Results show that the thermal efficiency of the v-groove collector is approximately $70 \%$ at a mass flow rate of $0.031 \mathrm{~kg} / \mathrm{m}^{2} \mathrm{~s}$. From many years, several studies using different corrugated absorber plate were reported in the literature.

Theoretical and experimental investigations were performed in order to investigate the thermal performance of solar air collector under single [8-19] or double air pass operations. Though, thermal performances of such solar collectors were compared with flat plate solar collectors. Many studies have depicted that use of corrugated absorber plate as an absorber is one of the best techniques to enhance thermal performance of the solar collectors by increasing the air turbulence and heat transfer area to the air. Hence the use of corrugated absorber plate is an effective way of enhancement of heat transfer in a solar air heater. 


\section{Porous absorber}

The nature of solar energy is intermittent, thus storage is required for uninterrupted supply of heated air in order to match the needs. Packed beds are generally used for storage of thermal energy from solar air heaters. A packed bed is a volume of porous media obtained by packing particles of selected material into a duct. A number of studies carried out on packed beds for their performance analysis are reported in the literature. These studies included the design of packed beds, materials used for storage, heat transfer enhancement, flow phenomenon and pressure drop through packed beds. Solar collectors with porous absorbers packed beds have been found to be more efficient as compared to conventional collector because they have high heat transfer rates. In such an absorber the solar radiation penetrates to greater depths and is absorbed gradually depending on the density of the packing.

Heat losses associated with a higher absorber temperature are reduced resulting in an improvement in the thermal efficiency of the collectors. Use of porous beds for the enhancement of collector performance has been shown to have certain specific advantages over the other methods. Packed bed solar air heater having its bed packed with semitransparent materials like glass beads, porcelain beads and glass tubes was investigated, theoretically and experimentally by Hasatani et al. [20]. The energy balance equations were solved numerically to obtain the collector performance. Based on the analysis and experimentation, it was reported that solar air heater having semi-transparent materials for the heat collector-cum-storage has 15-20\% higher efficiency of the energy collection as compared to that of a smooth collector.

Bhagoria et al. [21] have used mild steel chips as a packed bed material and compared the performance of the packed bed solar collector with that of marble chips packed bed solar air collector. It was obtained that steel chips packed bed solar collector give better performance that marble chips packed bed solar air collector. Studies performed using these packed bed materials indicates that thermal performance of such solar air collectors is better than flat plate solar air collectors.

\section{Artificial roughness on the surfaces}

Efficiency of flat plate solar air heater is low because of low convective heat transfer coefficient between absorber plate and flowing air which in turn increases the absorber plate temperature, leading to higher heat losses to the environment. The low value of heat transfer coefficient is generally attributed to the presence of a viscous sub-layer adjacent to the wall, which can be broken without disturbing the turbulent core to keep the pressure drop at low level by providing the absorber plate with artificial roughness in the form of fine wires, ribs and protrusion of different geometries [28-42].

\section{METHODOLOGY OF ARTIFICIAL ROUGHNESS}

The concept of artificial roughness was given by Joule [22]. Author enhances the heat transfer coefficient for in-tube condensation of steam. The artificial roughness on the absorber plate breaks the laminar sub layer region which is the barrier to the heat transfer between the flowing air and heated absorber plate. Artificial roughness on the absorber plate generates the turbulence which enhances the fluid mixing hence increase in the heat transfer rate but pumping power required for the flow to occur. As the air flows over the heated absorber, a viscous sub-layer (laminar) appears in the vicinity of the absorber. This sub-layer is resistant to the heat transfer between the absorber and the fluid (air). To break it, artificial roughness are provided on the absorber surface. The obstacles or rough elements, whatever their shape, are generating secondary flows or re-circulations, which result in two separation zones on both sides of the obstacle. The generated vortices are responsible of the turbulence and thus increase the heat transfer and pressure losses. Secondary fluid circulation promote a better convective heat transfer. However, it is desirable that the turbulence takes place only in the near-wall region, that is to say within the laminar sub-layer, where the heat transfer takes place, to minimize friction losses, Bhatti [22]. This is achieved by keeping the height of the rough element relatively small in comparison to duct dimensions. For remind, the laminar sub-layer thickness is given by [23].

$$
\delta_{\mathrm{t}}=5 \frac{v}{u_{\mathrm{f}}}
$$

for a smooth surface, we have [24],

$$
\begin{gathered}
\mathrm{u}^{+}=\mathrm{u} \sqrt{\frac{\tau_{W}}{\rho}} \\
\mathrm{y}^{+}=\mathrm{y} \frac{\sqrt{\frac{\tau_{W}}{\rho}}}{v}
\end{gathered}
$$

where,

$\tau_{w}=\rho u^{* 2}$ is called shear stress at the laminar wall

velocity,

$\mathrm{u}^{+} \quad$ is known as non dimensional velocity,

$$
\sqrt{\frac{\tau_{W}}{\rho}}=u^{*} \quad \text { is called frictional }
$$

$$
\mathrm{y}^{+} \quad \text { is non dimensional }
$$

distance from wall,

$$
v \quad \text { is kinematic viscosity }
$$

and we have,

$$
\mathrm{u}^{+}=\mathrm{y}^{+}
$$$$
\mathrm{y}^{+} \leq 5
$$
for laminar sub layer , 


$$
\mathrm{u}^{+}=5 \ln \mathrm{y}^{+}+3.5 \quad \text { for transition layer(buffer }
$$

layer), $5 \leq \mathrm{y}^{+} \leq 30$

$$
\mathrm{u}^{+}=2.5 \ln \mathrm{y}^{+}+5.5 \quad \mathrm{f} \text { or turbulent boundary }
$$

layer, $\mathrm{y}^{+} \geq 30$

There are some basic dimensionless geometrical parameters that are used to characterize roughness [25]:

Relative roughness pitch $(\mathrm{P} / \mathrm{e})$ : it is defined as the ratio of distance between two consecutive ribs (p) and height of the rib (e).

Relative roughness height (e/D): Relative roughness height $(\mathrm{e} / \mathrm{D})$ is the ratio of rib height (e) to equivalent diameter of the air duct (D).

Angle of attack $(\alpha)$ : Angle of attack is inclination of rib with direction of air flow in duct.

Aspect ratio (W/H): It is the ratio of duct width to duct height. This factor also plays a $\mathrm{v}$ ery crucial role in investigating thermo-hydraulic performance.

The turbulent flow induced by presence of obstacles is very complex to study that is why it is very difficult to develop analytical models to predict the fluid motion. One of the first study reported on the rough surfaces was provided by Joule [22] to enhance heat transfer coefficient for steam in tube condensation. We could also cite Nikuradse [26] who made an attempt to approach the velocity and temperature distribution on a rough surface . Webb and Eckert [27] developed heat transfer and friction factor correlations for turbulent air flow in tubes having rectangular repeated rib roughness based on the law of wall similarity and application of the heat-momentum transfer analogy to flow over rough surface having relative roughness height of $0.01-0.04$ at a relative roughness pitch of $10-40$ and range of Prandtl number of 0.71-37.6.

\section{A. Roughness geometry used in solar air heater ducts}

To enhance the thermal performance of solar air heater several types of roughness geometry shapes are employed on the absorber plate. These roughness are classified as regular roughness and irregular roughness. Regular roughness are of many types depending on the shape, orientation and arrangement of the roughness elements on the absorbers plates. The regular geometric roughness may be classified on the basis of shape of rib (rectangular, circular, wedge, chamfered), orientation (transverse, inclined, V shape), arrangement on surface (continuous, discrete, staggered), cavity (groove, pits/dimples) and impermeable or porous rib.

Some of the experimental as well as numerical investigations on the roughness geometry are cited to study the effect of artificial $\mathrm{g}$ eometric roughness on the heat transfer and friction factor. This includes both regular and irregular roughness of geometry.
1. Transverse, Inclined, V-discrete and V-continuous shaped roughness geometry

Karwa et al. [28] investigated experimentally thermohydraulic performance of a solar air heater with $60^{\circ} \mathrm{V}$-down discrete rib roughness on the airflow side of the absorber plate along with that for a smooth duct air heater as shown in fig. 1 (a) and 1 (b). The enhancement in the thermal efficiency due to artificial roughness on the airflow side of the absorber plate has been found to be $12.5-20 \%$ depending on the

(a)

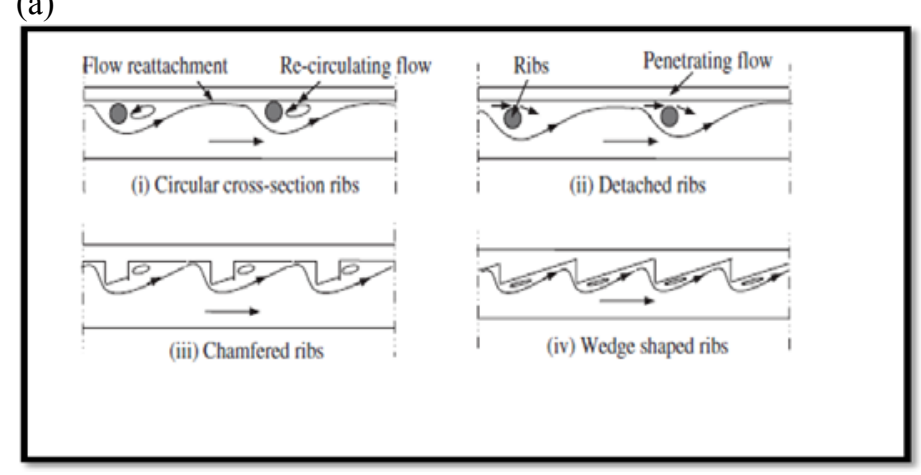

(b)

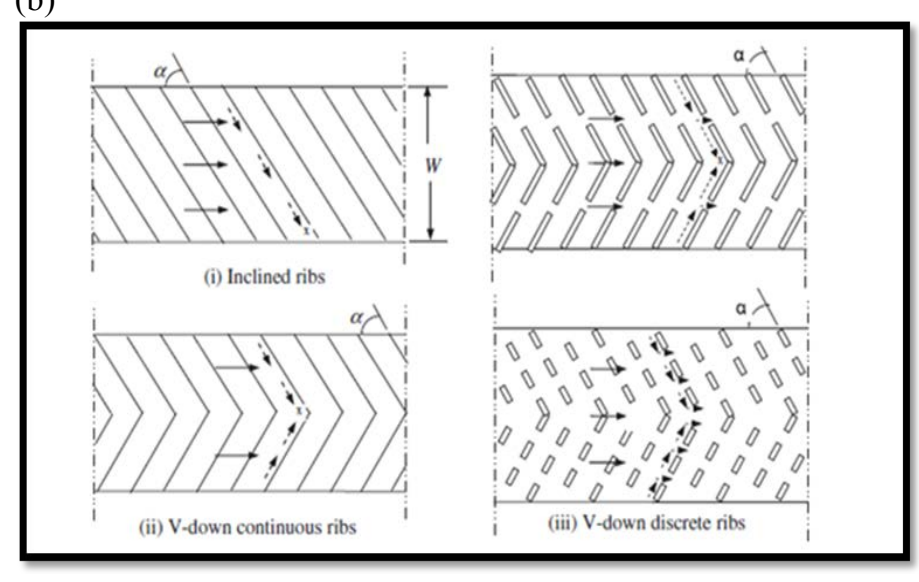

Fig. 1 Effect of rib shape (b) Effect of rib orientation [28]. flow rate, higher enhancement is at the lower flow rate, which is attributed to the enhancement in the heat transfer coefficient due to the employment of the roughness.

\section{RESEARCH METHODOLOGY}

\section{A. Theory of the Novel Solar Air Heater}

In the present study, a novel solar air heater is considered for the heat transfer enhancement. In convention model of solar air heater the provision of the artificial roughness of various geometries on the absorber plate have remained limited only to one side (top side) of solar air heater duct. But in current study, artificial roughness on the three sides of solar air heater design along with parallel flow arrangement is considered. Two air stream of equal Reynold number through two ducts is considered for heat transfer enhancement. First of all optimization of the duct is done 
for the maximum thermal efficiency. Three cases are studied for the double duct optimization on the basis of maximum thermal efficiency:

1. Same hydraulic diameter of the inner and outer ducts $\left(D_{h 1}=D_{h 2}\right)_{3}$

2. Hydraulic diameter of the outer duct is greater than inner $\left(D_{h 1}>D_{h 2}\right)$ and
3. Hydraulic diameter of the outer duct is less than inner duct $\left(D_{h 1}<D_{h 2}\right)$.

After optimizing the hydraulic diameter of double duct solar air heater for the maximum thermal efficiency, transverse square sectioned ribs are employed on the both sides of the optimized duct. The square sectioned ribs are employed in a transverse continuous fashion along the length of absorber plate.

(a)

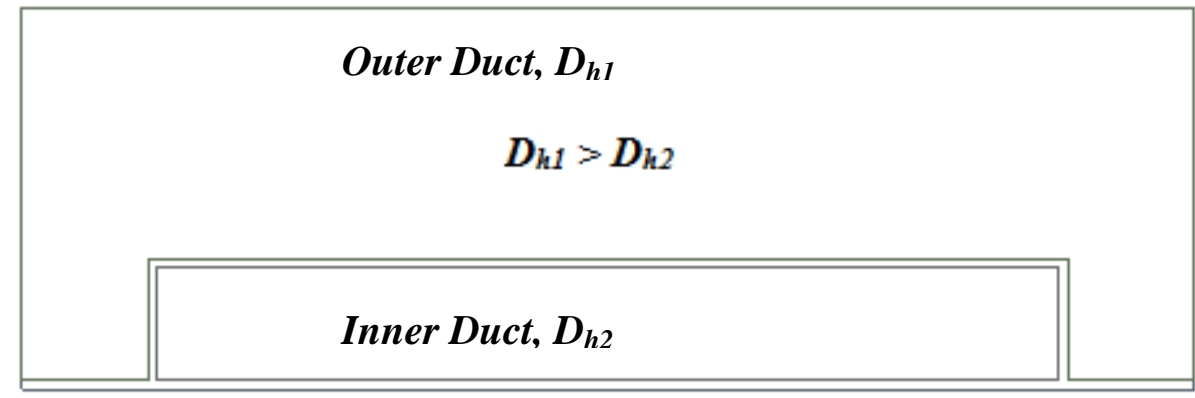

(b)

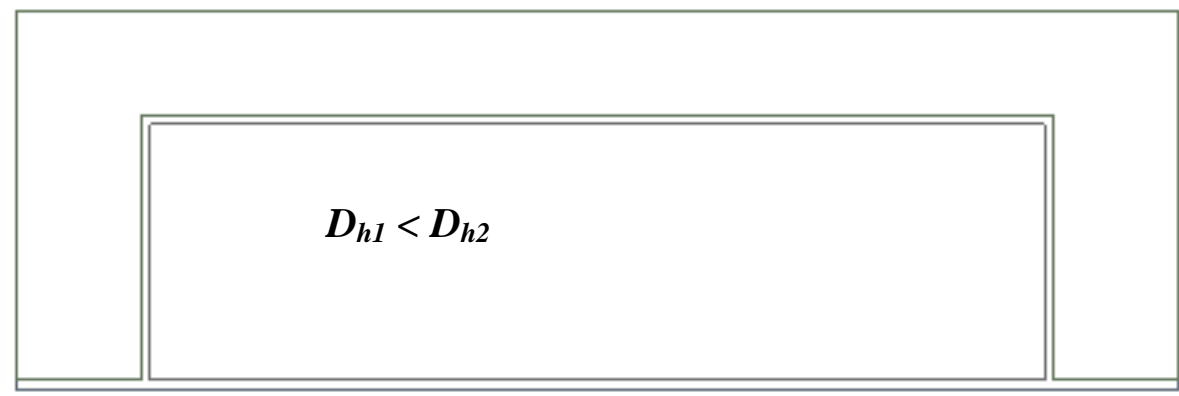

(c)

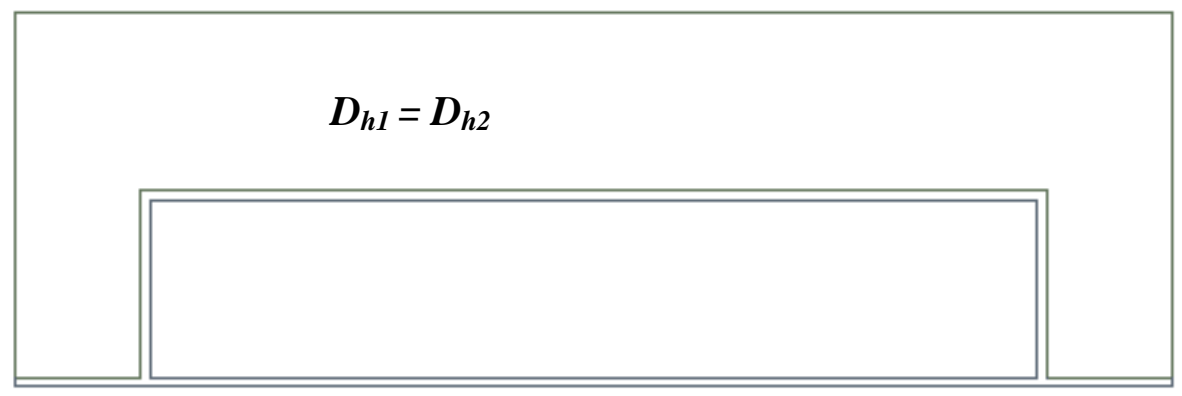

Fig. 2 Optimization of the double duct solar air heater (a) hydraulic diameter of the outer duct is greater than inner duct ( $\left.D_{h 1}>D_{h 2}\right)$, (b) hydraulic diameter of the outer duct is less than inner duct $\left(D_{h 1}<D_{h 2}\right)$ and (c) hydraulic diameter of the outer duct is equal to inner duct $\left(D_{h 1}=\right.$ $\left.D_{h 2}\right)$.

\section{B. Mathematical Model of Solar Air Heater}

Considering the air flow in the channel with heat transfer, the mathematical model is composed of the conservation equations of mass, momentum and energy for incompressible flow in three dimensions with the following assumptions:

1. The flow is turbulent, steady state and incompressible.

2. The thermo-physical properties of the air are supposed to be constant.
3. The thermal conductivity of the walls and ribs is supposed to be constant.

Governing equation of the fluid flow and heat transfer in solar air heate $r$ are as follows:

Continuity equation:

$$
\left(\frac{\partial u}{\partial x}+\frac{\partial v}{\partial y}+\frac{\partial w}{\partial z}=0\right)
$$


Momentum equations:

$\mathrm{x}$-momentum equation:

$$
\left(u \frac{\partial u}{\partial x}+v \frac{\partial u}{\partial y}+w \frac{\partial u}{\partial z}\right)=-\frac{1}{\rho}\left(\frac{\partial p}{\partial x}\right)+v\left(\frac{\partial^{2} u}{\partial x^{2}}+\frac{\partial^{2} u}{\partial y^{2}}+\frac{\partial^{2} u}{\partial z^{2}}\right)
$$

$\mathrm{y}$ - momentum equation:

$$
\left(u \frac{\partial v}{\partial x}+v \frac{\partial v}{\partial y}+w \frac{\partial v}{\partial z}\right)=-\frac{1}{\rho}\left(\frac{\partial p}{\partial y}\right)+v\left(\frac{\partial^{2} v}{\partial x^{2}}+\frac{\partial^{2} v}{\partial y^{2}}+\frac{\partial^{2} v}{\partial z^{2}}\right)
$$

z- momentum equation:

$$
\left(u \frac{\partial w}{\partial x}+v \frac{\partial w}{\partial y}+w \frac{\partial w}{\partial z}\right)=-\frac{1}{\rho}\left(\frac{\partial p}{\partial z}\right)+v\left(\frac{\partial^{2} w}{\partial x^{2}}+\frac{\partial^{2} w}{\partial y^{2}}+\frac{\partial^{2} w}{\partial z^{2}}\right)
$$

Energy equation:

$$
\left(u \frac{\partial T}{\partial x}+v \frac{\partial T}{\partial y}+w \frac{\partial T}{\partial z}\right)=\alpha\left(\frac{\partial^{2} T}{\partial x^{2}}+\frac{\partial^{2} T}{\partial y^{2}}+\frac{\partial^{2} T}{\partial z^{2}}\right)
$$

where,

$$
\alpha=\frac{k}{\rho C_{\mathrm{p}}}
$$

$\alpha$ is called thermal diffusivity.

Since the flow is turbulent, we used Reynolds decomposition to write,

$u=\bar{u}+\hat{u}$

where, $\bar{u}$ - mean velocity

$$
\rho\left(\frac{\partial \overline{u u}}{\partial x}+\frac{\partial \bar{u} \bar{v}}{\partial y}+\frac{\partial \bar{u} \bar{w}}{\partial z}\right)=-\left(\frac{\partial p}{\partial x}\right)+\mu\left(\nabla^{2} \bar{u}\right)-\frac{\partial\left(\rho \overline{u^{2}}\right)}{\partial x}-\frac{\partial(\rho \overline{u v})}{\partial x}-\frac{\partial\left(\rho \bar{u} w^{x}\right)}{\partial x}
$$

eqn. 2.4 and 2.5 are called RANS equations (Reynoldsaveraged Navier Stokes Equations). where, $\left(-\rho \overline{\left.u^{i} v^{v}\right)}\right.$ represents the Reynolds stress tensor and must be modeled correctly in order to get simulation results close to actual flow conditions.Hence above described governing equation of the fluid flow and heat transfer for solar air heater are discretized in FLUENT solver using finite volume approach.

\section{CFD Approach to Present Study}

In the present study three dimensional turbulent flow solar air heater with transverse continuous square sectioned rib on the both sides of the absorber plate is simulated. A general purpose CFD code, ANSYS FLUENT a co mmercial CFD package, is chosen for fluid flow and heat transfer simulation of artificially roughened solar heater. A CFD tool Ansys-fluent is used to solve the basic governing equation of the fluid flow. Ansys-Fluent implements finite volume method to solve the governing equation of the fluid flow.ANSYS Fluent employment process in the present work is shown in fig.2.2. Sketch of the computation domain is done in the design modeler. All the geometric parameters are defined in the design modeler and sketch of the computational domain is exported to ANSYS ICEM CFD meshing where computational domain is divided into number of grids which may be structured or unstructured depending upon the complexity of the geometry. At last the governing equations are solved in the Fluent solver with the suitable algorithms.

\section{Computation Solution Domain of The Problem}

Computational domain of the proposed solar air heater is three dimensional double duct solar air heater with square sectioned rib employed on the both sides of the absorber plate is shown in fig. 2. In the present work, transverse continuous square sectioned ribs are considered. The square rib height has been taken as $1 \mathrm{~mm}, 1.4 \mathrm{~mm}$ and $2 \mathrm{~mm}$, so that laminar sub-layer would be of the same order as of roughness height and fin/flow passage blockage effect can be avoided.

Present CFD analysis has been performed on nine different configurations of square sectioned transverse rib roughness on the absorber plate, at five different values of Reynolds number. Thus, a total of forty five different combinations of roughness height (e), roughness pitch (P) and Reynolds number (Re) have been investigated for the thermal performance. The range of Reynolds number has been chosen as $2500-16,000$ with five different values. 


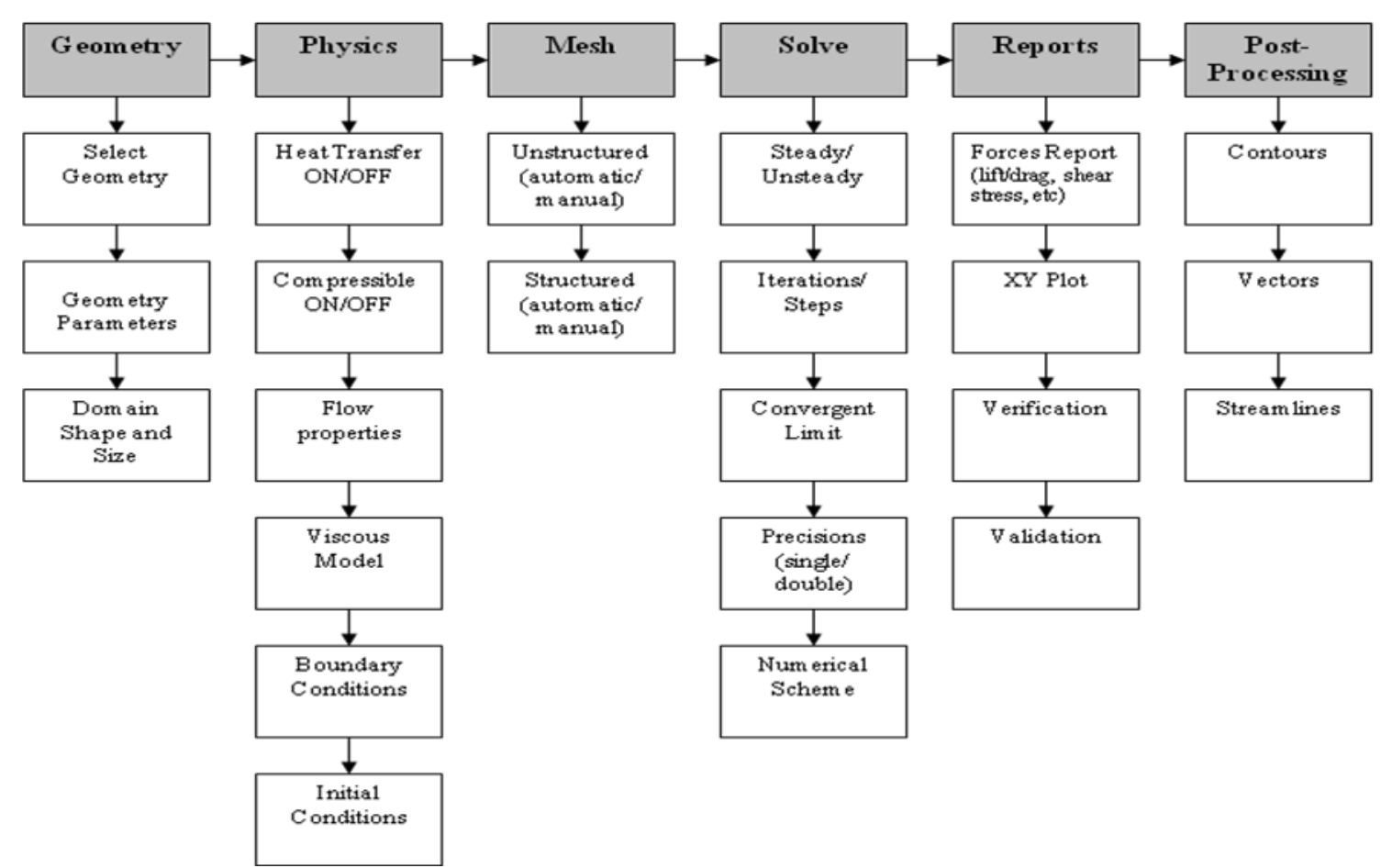

Fig. 3 Ansys Fluent employment process

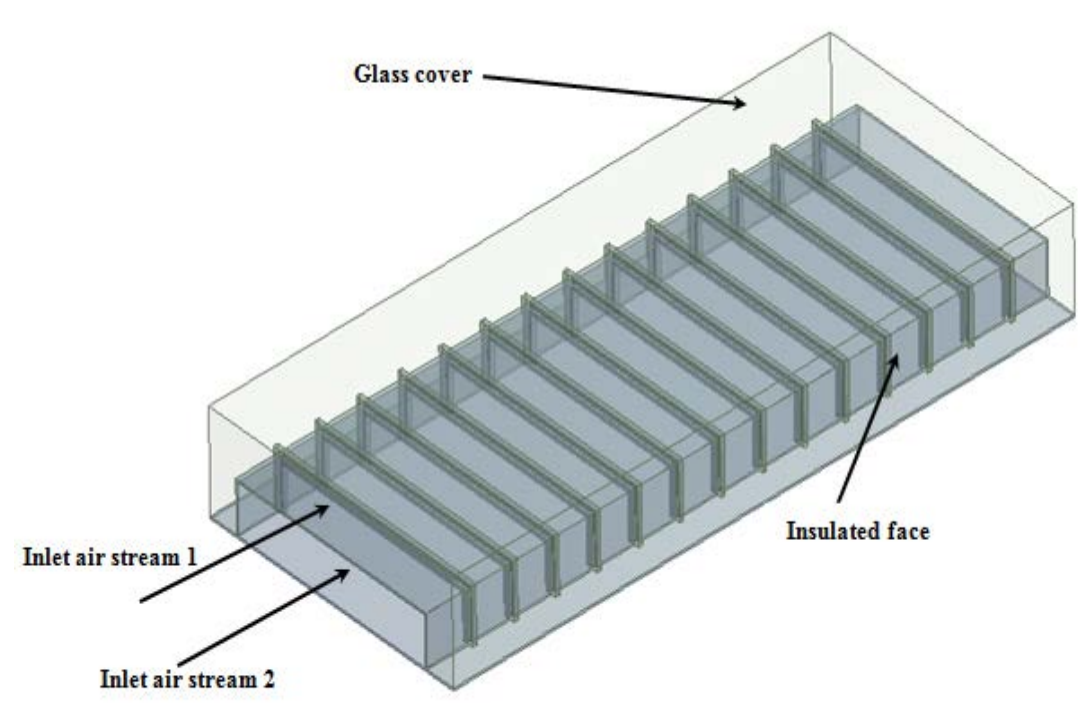

Fig. 4 Sketch of the computational Domain

Solar air heater is operated under three set of relative roughness height viz. $0.03,0.042$ and 0.06 under five different values of the Reynold number. Similarly, rib pitch is also varied as 10,15 , and 20 to examine the effect of rib pitch on the fluid flow and heat transfer characteristics.

On the top of the computational domain solar radiation fall on the glass cover. Solar radiation model named "Discrete ordinate" is used in order to apply solar loading on the glass cover.

Global radiation of $1000 \mathrm{~W} / \mathrm{m}^{2}$ falls on the glass cover. The absorptivity of the absorber plate should as high as possible so that all of the incoming radiation should be absorbed so that temperature of the absorber plate is increased. The duct wall, absorber plate and roughness material are homogeneous and isotropic. No slip boundary condition is given to the wall in contact with the fluid in the model.

The operating parameters employed in the computational domain are listed in table II. The working fluid in all the cases is air and the values of the thermo-physical properties of air has been assumed to be constant and evaluated at a temperature $300 \mathrm{~K}$. 
TABLE I GEOMETRICAL PARAMETERS OF THE PROPOSED SOLAR AIR HEATER

\begin{tabular}{|l|c|}
\hline Parameters (Solar air heater duct Parameters) & Values \\
\hline Collector length, $\mathrm{L}$ & $300 \mathrm{~mm}$ \\
\hline Duct width, W & $130 \mathrm{~mm}$ \\
\hline Hydraulic diameter of duct (inner and outer) & $33.33 \mathrm{~mm}$ \\
\hline Height of solar air heater duct, H & $41.10 \mathrm{~mm}$ \\
\hline Height of inner rectangular duct & $20 \mathrm{~mm}$ \\
\hline Rib height, e & $1-2 \mathrm{~mm}$ \\
\hline Number of glass covers, N & 1 \\
\hline
\end{tabular}

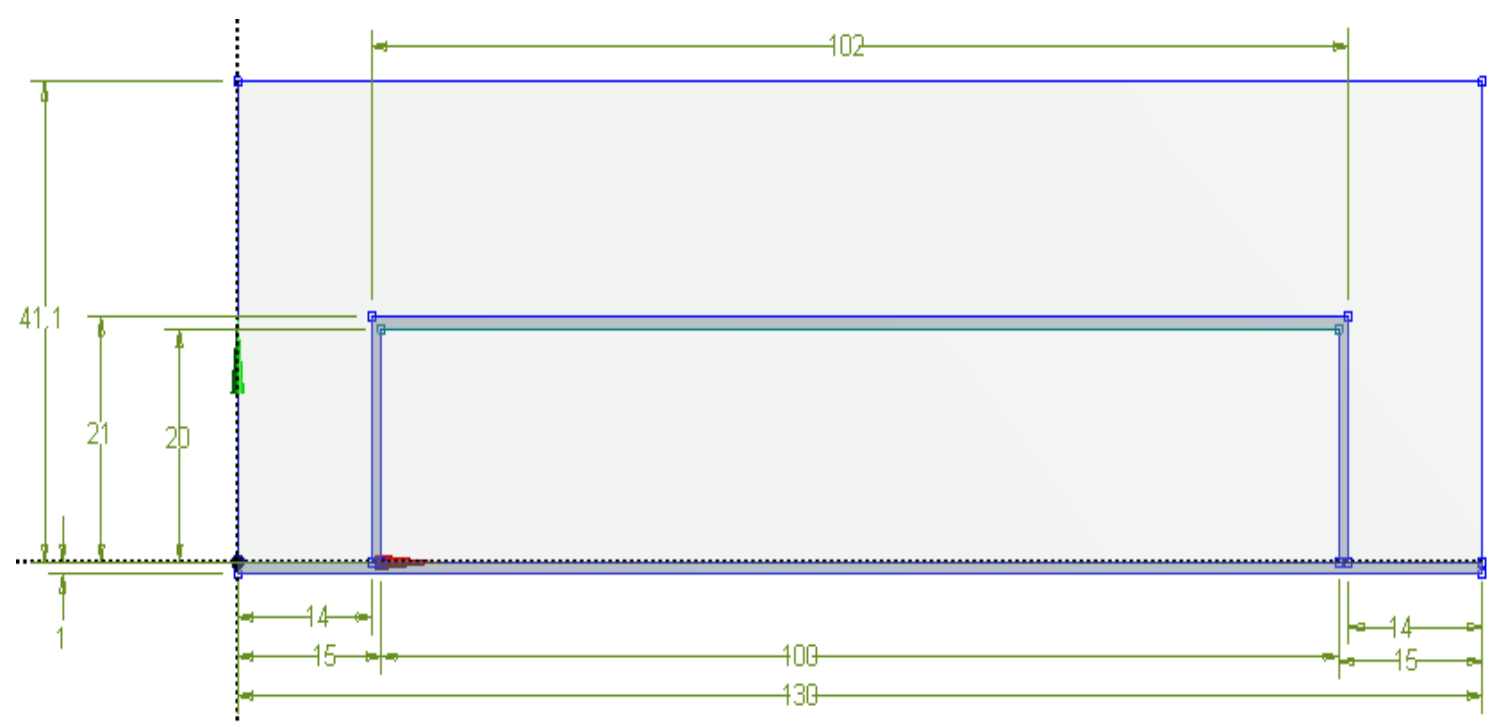

Fig. 5 Front view of proposed solar air heater with all dimensions in $\mathrm{mm}$

TABLE II NINE DIFFERENT CONFIGURATION OF SQUARE RIB USED IN THE PRESENT CFD INVESTIGATION

\begin{tabular}{|c|c|c|c|c|}
\hline $\begin{array}{c}\text { Hydraulic diameter of the duct, inner } \\
\text { and outer ( mm) }\end{array}$ & $\begin{array}{c}\text { Rib height, e ( } \\
\mathbf{m m})\end{array}$ & $\begin{array}{c}\text { Relative roughness } \\
\text { height, e/ }\end{array}$ & $\begin{array}{c}\text { Rib pitch, } \\
\text { P ( mm) }\end{array}$ & $\begin{array}{c}\text { Relative roughness } \\
\text { pitch, P/e }\end{array}$ \\
\hline 33.33 & 1 & 0.03 & 10 & 10 \\
\hline & & & 15 & 15 \\
\hline & & & 20 & 20 \\
\hline 33.33 & 1.4 & 0.042 & 10 & 7.14 \\
\hline & & & 15 & 10.71 \\
\hline 33.33 & & & 20 & 5 \\
\hline & 2 & 0.06 & 10 & 7.5 \\
\hline & & & 15 & 10 \\
\hline
\end{tabular}

\section{RESULTS \& DISCUSSIONS}

The heat transfer enhancement and pressure drop characteristics of a d ouble duct solar air heater using artificial roughness are investigated by using CFD approach. The double duct of the solar air heater is firstly optimized on the basis of hydraulic diameter for the maximum thermal efficiency, secondly for the optimized $d$ uct the effect of Reynolds number, relative roughness pitch $(\mathrm{P} / \mathrm{e})$ and relative roughness height $(\mathrm{e} / \mathrm{D})$ on the average heat transfer and fluid friction are considered in this chapter. Moreover, the results have been compared with those obtained in case of smooth ducts operating under similar operating conditions to discuss the enhancement in heat transfer and fluid flow characteristics on account of artificial roughness. Thermal performance of solar air heater is then delineated in terms of Nusselt number and friction factor. 


\section{A. Validation of the Proposed Solar Air Heater Model}

As we know that validation is the most important part in any numerical investigation in order to build confidence in study. Hence firstly selection of turbulence models is done by comparing the numerical results with the corresponding empirical correlation for smooth solar air heater. Secondly validation of proposed solar air duct is made with available literature. For validation dimension of smooth duct is taken as in accordance with Yadav et al.

\section{Selection and validation of the appropriate turbulence model for CFD analysis}

In order to select appropriate turbulence model for the simulation of artificially roughened solar air heater, the Nusselt number predicted by five different turbulence models namely, Standard k- $\varepsilon$, RNG (Renormalization-group) $\mathrm{k}-\varepsilon$, Realizable k- $\varepsilon$, Standard k- $\omega$ and SST (Shear stress transport) $k-\omega$ model are compared with the empirical correlation available for smooth duct of a solar air heater i.e. Dittus-Boelter equation and it is found that RNG (Renormalization-group) $\mathrm{k}-\varepsilon$ model gives closer result to Dittus-Boelter equation with a maximum deviation of 9.24\%. Fig. 3.1 shows the comparison between Nusselt number predicted using different CFD turbulence model with Dittus-Boelter empirical correlation for smooth duct of a solar air heater.

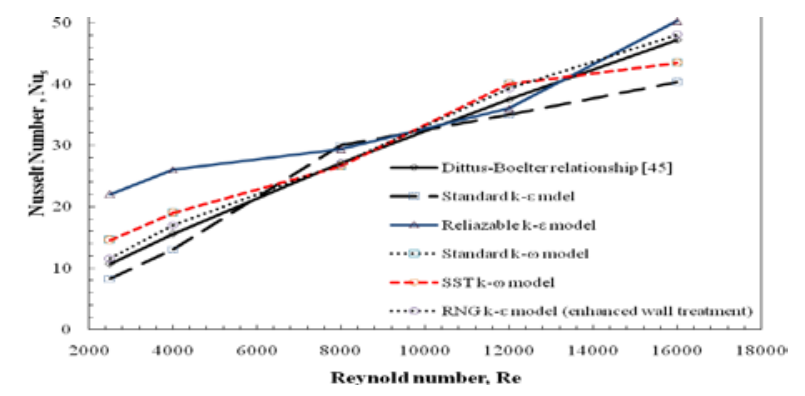

Fig. 6 Comparison between Nusselt number predicted using different CFD turbulence model with Dittus-Boelter empirical correlation for smooth duct of a solar air heater.

2.Validation of the inner and outer smooth duct with Dittus Boelter empirical correlation

Both inner (rectangular duct) and outer smooth ducts of double duct solar air heater are validated with Dittus Boelter empirical correlation in order to validate the numerical study in case of a smooth duct.

The present analysis is for a novel type of solar air heater, and therefore, direct validation of the numerical $d$ ata could not be possible. However, in light of previous numerical data of the heat transfer parameter in case square transverse ribbed rectangular duct solar air heater of Yadav et al. is analyzed for the same operating conditions. The heat transfer parameter is found to be in agreement with Yadav et al. at a relative roughness height (e/D) of 0.03 and
0.042 with corresponding relative roughness pitch $(\mathrm{P} / \mathrm{e})$ of 10 and 7.14 respectively. Verification of numerical methods and CFD code is carried out through grid independent test. A rigorous grid refinement study is performed, which also a methodology for verification of CFD calculations.

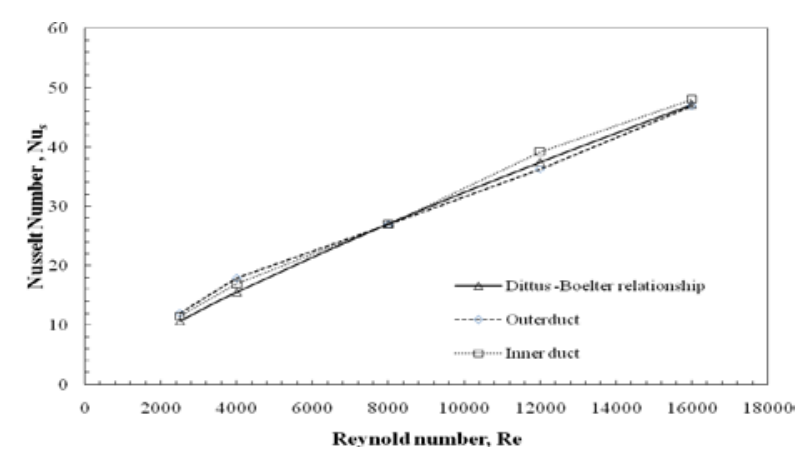

Fig. 7 Validation of inner and outer smooth duct of double duct solar air heater with Dittus-Boelter empirical correlation using RNG k$\varepsilon$ turbulence model.

\section{Verification and validation of the proposed artificially roughened solar air heater}

Verification and validation are essential methods to be used during the development of simulation of physical processes using CFD techniques.

\section{(a)}

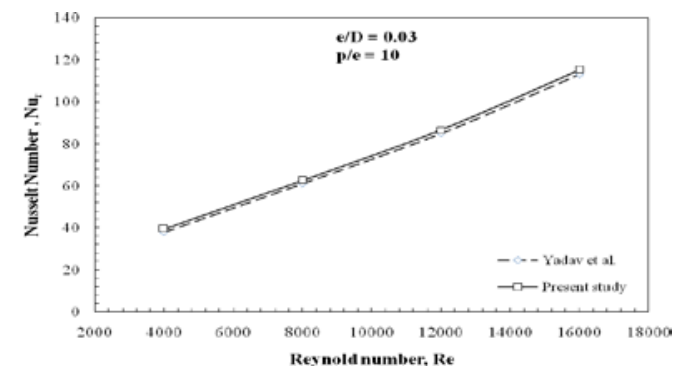

(b)

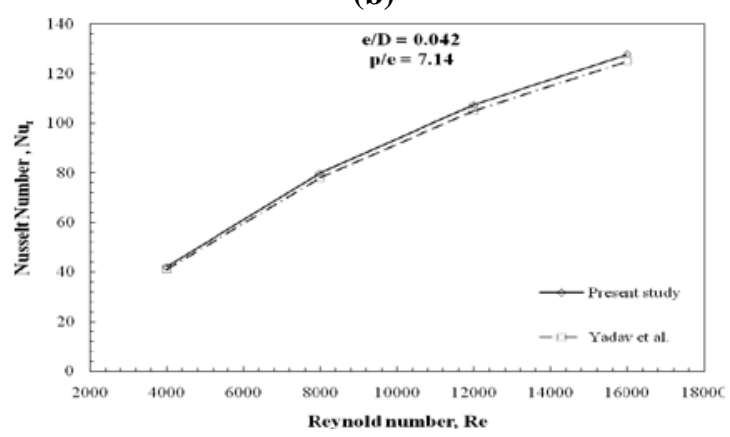

Fig. 8 Validation of CFD model with Yadav et al. for transverse rib roughness with (a) $\mathrm{e} / \mathrm{D}=0.03, \mathrm{P} / \mathrm{e}=10$ and (b) $\mathrm{e} / \mathrm{D}=0.042$, $\mathrm{P} / \mathrm{e}=7.14$

Tests for the confirmation of grid independence of the proposed model is carried out by increasing the grid density until difference in two consecutive sets of results is less than $1 \%$. For grid independence test, the number of cells is varied from 340,810 to 750,890 in three steps. Three different grid distributions are tested on square sectioned 
transverse ribs, with rib height of $1.4 \mathrm{~mm}$, pitch of $10 \mathrm{~mm}$ and Reynolds number of 12,000 , to ensure that the calculated results are grid independent.

\section{B. Results of Double Duct Solar Air Heater with Square Transverse Continuous Ribs}

In this section results of the double duct solar air heater are presented. First of all, results of variation of hydraulic diameter for the maximum thermal efficiency are presented comprehensively. Then the heat transfer and fluid flow characteristics in terms of Nusselt number and friction factor are described.

\section{Optimization of double solar air heater}

The effect of hydraulic diameter on the thermal performance of double duct solar air heater is considered. Three cases are studied for the double duct solar air heater on the basis of hydraulic diameter for the maximum thermal efficiency:

1. Same hydraulic diameter of the outer and inner ducts $\left(D_{h 1}=D_{h 2}\right)$,

2. Hydraulic diameter of the outer duct is greater than inner duct $\left(D_{h 1}>D_{h 2}\right)$,

3. Hydraulic diameter of the outer duct is less than inner duct $\left(D_{h 1}<D_{h 2}\right)$.

As discussed in previous chapter, hydraulic diameter of the both duct is varied in order to get optimized duct for the current study. Thermal efficiency is calculated for all of the above three cases discussed at three different mass flow rates viz. $0.01,0.015$ and 0.02 and thermal efficiency is found to be maximum when the hydraulic diameter of the inner and outer ducts is same i.e. $D_{h 1}=D_{h 2}$. The results in case of varied hydraulic diameters is shown in fig. 9.

Hence it is found that when the hydraulic diameter of inner and outer duct is kept same, maximum thermal efficiency of the solar air heater is achieved and thus this duct is used for employment of artificial roughness.

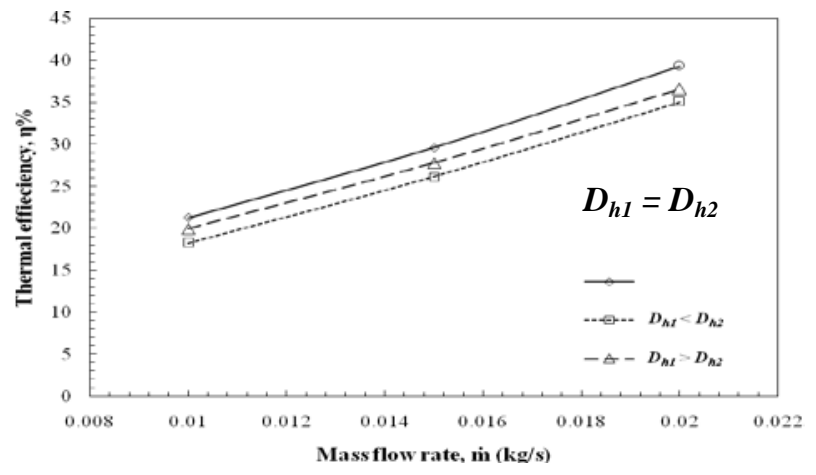

Fig. 9 Optimization of hydraulic diameter for inner and outer duct of solar air heater

\section{CONCLUSIONS}

A numerical investigation on heat transfer and fluid flow characteristics of proposed solar air heater is performed. A detailed description of the average heat transfer and fluid flow characteristics in terms of Nusselt number and friction factor, are obtained. The effects of Reynolds number, relative roughness pitch $(\mathrm{P} / \mathrm{e})$ and relative roughness height (e/D) on the heat transfer and fluid flow process are discussed. The following conclusions has been drawn on the basis of the present numerical investigation :

1. The use of double duct and three sided artificially roughened solar air heater in the form of square rib roughness effectively enhances the convective heat transfer coefficient, therefore the rate of heat transfer in comparison with smooth solar air heater.

2. Renormalization-group (RNG) $\mathrm{k}-\varepsilon$ turbulence model gives results very close to the Dittus-Boelter empirical correlation for smooth duct of a solar air heater which yields confidence in the prediction done by numerical analysis in the present study.

3. For the maximum thermal efficiency of double duct parallel flow solar air heater, the hydraulic diameter of both inner and outer duct should be equal.

4. The maximum enhancement of average Nusselt number has been found to be 11.30 times higher than that of a smooth duct for the relative roughness pitch of $10 \mathrm{a}$ nd relative roughness height of 0.06 at Reynold number of 4000.

\section{REFERENCES}

[1] J.P. Joule, "On the surface condensation of steam," philos Trans $R$ Soc Lond. No. 151, pp. 133-60, 1861.

[2] J. Nikuradse, "Law of flow in rough pipes," 1950.

[3] Bevil Brandt, Solar Energy, US 7434577B2, pp. 12-19, 1968.

[4] RL Webb and ERG Eckert, "Heat transfer and friction in tubes with repeated-rib roughness," Int J. Heat Mass Transfer, Vol. 14, pp. 601-17, 1971.

[5] T.M. Kuzey, M.A.S. Malik and KW. Boer, "Solar collectors of solar one. In: Proceedings of solar collectors heating cooling buildings," EDSL Sargent, College Park, New York City: Mary l and University, pp. 99-108, May, 1974.

[6] TL Ryan, GT Kallsz and Arlz Winslow, "Forced air solar heating system," US4278072, 1981.

[7] K. Prasad and S.C Mullick, "Heat transfer characteristics of a solar air heater used for drying purposes," Applied energy, Vol.13, No. 2, pp. 83-93, 1983

[8] HP Garg, G Datta and B Bandyopadhyay, "A study on the effect of enhanced heat transfer area in solar air heaters," Energy Conversion Management; Vol. 23, No. 1, pp. 43-9, 1983.

[9] MM Sorour and ZA Mottaleb, "Effects of design parameters on the performance of channel-type solar energy air heaters with corrugated plates," Applied Energy, Vol. 17, pp. 181-90, 1984.

[10] M Hasatani, Y Itaya and K Adachi, "Heat transfer and thermal storage characteristics of optically semi-transparent material packed bed solar air heater, current researches in heat and mass transfer," A compendium and festschrift for Prof. A. Ramachandran, ISHMT, Department of mechanical engineering, IIT Madras, India, pp. 61-70, 1985.

[11] MS Bhatti and RK Shah, "Turbulent and transition flow convective heat transfer in ducts," Hand book of single-phase convective heat transfer. New York: John Willey \& Sons, 1987. 
[12] BN Prasad, JS Saini, "Effect of artificial roughness on the heat transfer and friction factor in a solar air heater," Solar Energy, pp. 555-60, 1988

[13] C Choudhary, SL Andersen and J Rekstad, “ A solar air heater for low temperature application," Solar Energy, Vol. 40, pp. 335-43, 1988.

[14] V Smil, General energetics, "Energy in the biosphere and civilization," 1st ed. New York: John Wiley \& Sons; 1991.

[15] Rajendra Karwa, "Experimental study of augmented heat transfer and friction factor in asymmetrical heated rectangular duct with ribs on the heated wall in transverse, inclined, v-discrete and vcontinuous," PII: S0735-(03)0035-6, 1933.

[16] Dhananjay Gupta, S.C.Solanki and J.S.Saini, "Heat and fluid in rectangular solar air heater ducts having transverse rib roughness on absorber plates," Solar Energy, Vol. 51, No.1, pp. 31-37, 1993.

[17] N.K. Bansal, R. Chandra and M.A.S. Malik, "Solar Air Heater, Be views of Renewable Energy Sources," 1994.

[18] K.K. Matrawy, "New derivation and analysis for a combined solar storage system coupled with a finned absorber air collector," Journal of Energy Conversion Management, Vol. 38, pp. 861-9, 1998.

[19] N.K. Bansal, "Solar air heater applications in India," Renewable Energy, Vol.16, pp. 618-423, 1999.

[20] C Choudhary and HP Garg, "Design analysis of corrugated and flat plate solar air heaters," Renewable Energy, Vol. 5, pp. 595607, 1991.

[21] BF Parker, MR Lindey DG Colliver and WE Murphy, "Thermal performance of three solar air heaters," Solar Energy, Vol.51, no. 6, pp. 467-79, 1993.

[22] Y Piao, EG Hauptmann and M Iqbal, "Forced convective heattransfer in cross-corrugated solar air heaters," ASME Journal of Solar Energy Engg, Vol. 116, pp. 212-4, 1994.

[23] MN Metwally, HZ Abou-Ziyan and AM El-Leathy, "Collector compared with five conventional designs," Renewable Energy, Vol. 10, No. 4, pp. 519-37, 1997.

[24] JA Stasiek, "Experimental studies of heat transfer and fluid flow across corrugated-undulated heat-exchanger surfaces," International Journal of Heat Mass Transfer, Vol. 41, pp. 899-914, 1998.

[25] S Noorshahi, CA Hall and EK Glakpe, "Natural convection in a corrugated enclosure with mixed boundary conditions," ASME Journal of Solar Energy Engg, Vol. 118, pp. 50-7.

[26] JL Bhagoria, RM Sarviya and SS Arora, " Enhancement of heat transfer coefficient by using packed bed solar air heaters," In: Proceedings of the international conference on recent advances in solar energy conversion systems, Maulana Azad National Institute of Technology, Bhopal (M.P), India, pp. 96- 102, 2002.

[27] J.L. Bhagoria, J.S. Saini, S.C. Solanki, "Heat transfer coefficient and friction factor correlations for rectangular solar air heater duct having transverse wedge shaped rib roughness on the absorber plate," Renewable energy, Vol. 25, pp. 341-369, 2002.

[28] N. Moummi, S. Youcef-Ali, A. Moummi and J.Y. Desmons, "Energy Analysis of Solar Air Collector with Rows of fins," Renewable Energy, Vol. 29, pp. 2053-2064, 2004.
[29] R Verma, R Chandra and HP Garg, "Parametric studies on the corrugated solar air heaters with and without cover," Renewable Energy, Vol. 1, pp. 361-71, 2004.

[30] A.R. Jaurker J.S. Saini and B.K. Gandhi, "Heat transfer and friction factor characterstics of rectangular solar air heater duct using rib grooved artificial roughness," Solar Energy, Vol. 80, pp. 895-907, 2006.

[31] W Lin, W Gao and T Liu, "A parametric study on the thermal performance of cross-corrugated solar air collectors," Applied Thermal Engg, Vol. 26, pp. 1043-53, 2006.

[32] R.P. Saini and Jitendra Verma, "Heat transfer and friction factor correlations for a duct having dimple-shape artificial roughness for solar air heaters," Energy, Vol. 33, pp. 1277- 1287, 2008.

[33] Sharad Kumar, R.P. Saini , "CFD based performance analysis of a solar air heater duct provided with artificial roughness," Renewable Energy, Vol. 34, pp. 1285-1291, 2009.

[34] V.S Hans, R.P.Saini and J.S.Saini, "Performance of artificial roughened solar air heater- A Review," Renewable and Sustainable energy Review, Vol. 13, pp. 1854-1869, 2009.

[35] S.V. Karmare, A.N. Tikekar, "Analysis of fluid flow and heat transfer in a rib grit roughened surface solar air heater using CFD," Solar Energy, Vol. 84, pp. 409-41, 2010.

[36] Bhushan and Ranjit Singh, "A review on methodology of artificial roughness used in duct of solar air heaters," Energy, Vol. 35, pp. 202-212, 2010

[37] AB Boukkadoum and A Benzaoui, "CFD based analysis of heat transfer enhance- ment in solar air heater provided with transverse rectangular ribs," In:Proceedings of the international conference on Technologies and Materials for Renewable Energy, Environment and sustainability, Energy Procedia, Vol. 50, pp.761-72, 2014.

[38] Rajendra Karwa and Girish Chitoshiya, "Performance study of solar air heater having v-down discrete ribs on absorber plate ," Energy, Vol. 55, pp. 939-955, 2013.

[39] B.N. Prasad ,K Arun, L. Behura and Prasad, "Fluid flow and heat transfer analysis for heat transfer enhancement three sided artificially roughened solar air heater", Solar Energy, Vol. 105, pp. 27-35, 2014.

[40] K. Yongsiri, P. Eiamsa-ard, K. Wongcharee and S.Eiamsa-ard, "Augmented heat transfer in a turbulent channel flow with inclined detached-ribs," Case Studies in Thermal Engineering, Vol. 3, 110, 2014.

[41] Jin Dongxu, Manman Zhang Ping and Xu Wang Shasha, "Numerical investigation of heat transfer and fluid flow in a solar air heater duct with multi V-shaped ribs on the absorber plate," Energy, Vol. 89, pp. 178-190, 2015.

[42] Sukhmeet Singh, Bikramjit Singh, V.S. Hans and R.S. Gill, "CFD (computational fluid dynamics) investigation on Nusselt number and friction factor of solar air heater duct roughened with nonuniform cross-section transverse rib," Energy, Vol. 84, pp. 509$517,2015$. 